INOVAÇÃO DISRUPTIVA DIGITAL E CAPACIDADES DINÂMICAS: ESTRUTURAS E VÍNCULOS INTELECTUAIS

DIGITAL DISRUPTIVE INNOVATION AND DYNAMIC CAPACITIES: INTELLECTUAL STRUCTURES AND LINKS

Recebido em: 28 out. 2020

Aprovado em: 04 mar. 2021

Versão do autor aceita publicada online: 04 mar. 2021

Publicado online: 25 jun. 2021

Como citar esse artigo - American Psychological Association (APA):

Paiva, E. M., Pigola, A., \& Costa, P. R. (2023, jan./mar.). Inovação disruptiva digital e capacidades dinâmicas: estruturas e vínculos intelectuais. Exacta, 21(1), 147-172.

https://doi.org/10.5585/exactaep.2021.18598

Submeta seu artigo para este periódico $\mathcal{\theta}$

Processo de Avaliação: Double Blind Review

Editor: (D) Dr. Luiz Fernando Rodrigues Pinto

Dados Crossmark 



\title{
INOVAÇÃO DISRUPTIVA DIGITAL E CAPACIDADES DINÂMICAS: ESTRUTURAS E VÍNCULOS INTELECTUAIS
}

\author{
DIGITAL DISRUPTIVE INNOVATION AND DYNAMIC CAPACITIES: \\ INTELLECTUAL STRUCTURES AND LINKS
}

\author{
(iD) Eliane Martins de Paiva ${ }^{1}$ \\ Angélica Pigola ${ }^{2}$ \\ (iD) Priscila Rezende da Costa ${ }^{3}$
}

Resumo: O objetivo deste estudo é responder como está configurada a estrutura intelectual que vincula a inovação disruptiva digital às capacidades dinâmicas? Em virtude disso, o objetivo é identificar a estrutura e os vínculos intelectuais no campo conceitual a partir da análise de artigos científicos publicados no período de 1995 a 2019 em periódicos indexados à base de dados Web of Science. O método utilizado foi o bibliométrico com o apoio dos softwares VOSviewer e Iramuteq. Os resultados revelam a arquitetura do campo conceitual e as redes relacionais que vinculam as inovações disruptivas digitais à capacidade dinâmica, indicando que o campo é emergente e as relações tendem a se fortalecer e se estruturar. Esses achados abrem caminho para novas pesquisas em várias frentes.

Palavras chave: inovação disruptiva. inovação disruptiva digital. capacidades dinâmicas. bibliometria.

\footnotetext{
${ }^{1}$ elianempaiva@gmail.com - Universidade Federal da Paraíba - UFPB - Universidade Nove de Julho - UNINOVE - Doutoranda em Administração pela Universidade Nove de Julho. Mestrado em Engenharia de Produção pela Universidade Federal da Paraíba (1999). Graduação em Administração pela Universidade Federal da Paraíba. Atua como Professora Adjunta no Departamento de Ciências Sociais Aplicadas (DCSA) da Universidade Federal da Paraíba. Integra o Grupo de Pesquisa Núcleo de Estudos, Organização e Sociedade (NEOS), linha de pesquisa Estratégias e Organizações. Integra, ainda, GENOVE - Grupo de Estudo e Pesquisa em Inovação, Empreendedorismo e Negócios Sustentáveis - IEN. Tem experiência na área de Administração, com ênfase em Gestão da Produção, Gestão de estoques e Empreendedorismo e inovação com interesses em Inovação disruptiva, transformação digital, gestão da inovação, ecossistema de inovação, Ecossistemas de empreendedorismo intensivo em conhecimento e logística reversa

2 a_pigola@outlook.com.br - Universidade Nove de Julho - UNINOVE - Doutoranda em Administração pela Universidade Nove de Julho. Mestrado em Administração pela Universidade Nove de Julho (2020), Pós-Graduação em Administração de Marketing pela Fundação Armando Alvares Penteado FAAP (2001) e Graduação em Administração de Empresas (40505) pela Universidade Paulista UNIP (1995). 26 anos de experiência na área de Administração, com ênfase em Administração de Recursos Humanos trabalhando com Planejamento e Estratégia de RH, Mudança de Gestão e Transformação de RH, Remuneração e Benefícios, Folha de Pagamento e Impostos, Negociações Laborais, Relações com Empregados, Treinamento e Desenvolvimento e Recrutamento. Desenvolvimento de políticas de RH, mapas de processos e procedimentos de Serviços Operacionais, Remuneração e Benefícios para o Brasil e América do Latina: Argentina, Brasil, Colômbia, Chile, Peru e México. Negociações Sindicais, Gestão de Cargos e Salários, Benefícios, Programas de Participação nos Lucros e Resultados, Desenvolvimento de Remuneração Estratégica e Gestão Sindical fizeram parte de projetos realizados. Realização de Planos de Recuperação e Emergência, Soluções de Resiliência para Recursos Humanos em Caso de Desastres. Apoiar Empresas em Fusões e aquisições trabalhando na gestão da mudança, apoiando aspectos regulatórios para as perspectivas de RH. Suporte a implementação de Serviço Global Compartilhado - implementação de HRIS, Portal de Autoatendimento de RH, Programa Esocial e Operações e Soluções de RH. Forte atuação na preparação dos processos contra fraude em folha de pagamento e Cyber-ataque contra as tecnologias de RH. Implementação e desenvolvimento de ferramentas de Gestão de Competências e avaliação de desempenho com aprovações electrónicas para a prestação de serviços de RH. Projetos de E-learning, Universidade Corporativa, Programa de Gestão de Desenvolvimento Executivo e Plano de Sucessão. 3 priscilarc@uni9.pro.br - Universidade Nove de Julho - UNINOVE - Doutora em Administração pela Universidade de São Paulo (FEA USP), 2012. Mestre em Administração pela Universidade de São Paulo (FEA RP USP), 2007. Graduada em Administração pela Universidade Federal de Lavras (UFLA), 2005. Atualmente é professora titular da Universidade Nove de Julho (UNINOVE), no Programa de Pós-graduação em Administração (PPGA). Coordena projeto de pesquisa financiado pelo CNPq ( $\left.n^{\circ} 471875 / 2014-7\right)$, intitulado Geração de Inovações para o Desenvolvimento Sustentável: Um Estudo com Empresas de Base Tecnológica de Economias Emergentes. Nos programas de Mestrado e Doutorado, leciona as disciplinas: Gestão e Internacionalização do Empreendedorismo Inovador e Tópicos Especiais em Inovação. É também avaliadora de periódicos na área de Administração, como: Revista de Gestão e Projetos, Exacta (Online), RAUSP, Revista de Administração, Contabilidade e Economia da FUNDACE (RACEF), Future Studies Research Journal, Internext, Gestão \& Regionalidade e Desenvolvimento em Questão. Participa dos seguintes grupos de pesquisa: Gestão e Modelos da Inovação (UNINOVE), Estratégia de Inovação (UNINOVE), Inovação e Sustentabilidade (UNINOVE), Núcleo de Política e Gestão Tecnológica da USP e do Núcleo de Pesquisas em Inovação, Gestão Empreendedora e Competitividade da USP. Tem experiência na área de Administração e seus principais temas de pesquisa são: cooperação empresa-universidade, capacidades dinâmicas, capacidade relacional, capacidade absortiva e internacionalização da inovação.
} 
Abstract: The aim of this paper is to answer how the intellectual structure linking digital disruptive innovation and dynamic capabilities is configured. Therefore, the aim is to identify the intellectual structure and links in the conceptual field through the analysis of scientific articles published between 1995 and 2019 in journals indexed on the Web of Science database. The bibliometric method was used with the support of VOSviewer and Iramutea software. The results reveal the architecture of the conceptual field and the relational networks linking digital disruptive innovations to dynamic capability, indicating that the field is emergent and relationships tend to strengthen and structure themselves. These findings pave the way for new research in several fronts.

Keywords: disruptive innovation. digital disruptive innovation. dynamic capabilities. bibliometry.

\section{Introduction}

Desde os primeiros trabalhos a respeito da inovação disruptiva (Christensen \& Bower, 1995) a pesquisa relativa a esse tema tem recebido crescente atenção. O caráter disruptivo da inovação se apresenta quando uma empresa, com recursos limitados, consegue desafiar com sucesso empresas tradicionais e estabelecidas no mercado ao introduzir um novo produto e/ou serviço que, inicialmente, apresenta um desempenho inferior em relação ao seu concorrente, mas promove uma mudança significativa no hábito e/ou comportamento de seus consumidores (Christensen, 1997; Christensen \& Bower, 1996). Ao provocar essa mudança no mercado (Nagy et al., 2016), causam turbulências e desarranjos que tendem a perturbar a indústria e as relações do ecossistema em que estão inseridas.

O desenvolvimento e a disseminação de tecnologias conectadas à internet abriram espaço para uma nova classe de inovação, a inovação digital (Elbanna \& Newman, 2016). Essa inovação pode ser entendida aqui como um processo que combina componentes digitais e físicos na criação de novos dispositivos, serviços ou modelos de negócios digitais, inseridos no mercado e incorporados a ambientes sociotécnicos mais amplos, que permitem sua difusão, operação e uso (Skog et al., 2018; Yoo et al., 2010).

Considerada um dos três elementos da disrupção digital (Skog et al., 2018), a pesquisa em inovação digital ainda está em fase embrionária e pouco se sabe sobre a natureza de seu impacto como elemento disruptivo. Não está claro se todos as categorias de inovação digital compartilham as mesmas características e que relações podem existir entres essas características, bem como, seu impacto perturbador (Elbanna \& Newman, 2016).

Devido à complexidade do tema, a literatura contemporânea sobre inovações disruptivas precisa ser revisitada, pois ainda carece de elucidações. Muitos estudos tratam do tema explicando os fatores e elementos de influência (Si \& Chen, 2020), revisam a teoria no sentido de esclarecer o seu conceito e interpretações equivocadas (Yu \& Hang, 2010). Por sua vez, Adner e Snow (2010) exploram as implicações de uma alternativa para tentar a transformação necessária para adotar uma nova tecnologia dominante, examinando a decisão de permanecer com a tecnologia antiga como uma escolha racional e proativa. 
Para responder às inovações disruptivas digitais, Riemer e Johnston (2019) apontam razões pelas quais incumbentes falham em detectar ou lidar com inovações disruptivas, e a literatura, frequentemente, examina os recursos e as capacidades dos incumbentes (Karimi \& Walter, 2015) para tentar explicar esses desafios. A abordagem das Capacidades dinâmicas tem se mostrado uma forma eficiente de responder às disrupções.

Shang e tal. (2019) propõem um estudo bibliométrico sobre inovação disruptiva digital desde o ano 1997 a 2016, permitindo um quadro amplo da base de conhecimento. A partir da pesquisa de Karimi e Walter (2015) percebeu-se uma lacuna nos estudos vinculando inovação disruptiva digital às capacidades dinâmicas.

Por isso, este trabalho visa responder à seguinte questão de pesquisa: como está configurada a estrutura intelectual que vincula a inovação disruptiva digital às capacidades dinâmicas? Para elucidar esta questão buscou-se identificar e compreender a estrutura intelectual que relaciona a disrupção digital às capacidades dinâmicas a partir da análise de artigos científicos publicados no período de 1995 a 2019 em periódicos indexados à base de dados Web of Science (WoS). Para operacionalizar o objeto do estudo, é importante identificar como a estrutura da produção científica tem evoluído ao longo do tempo; analisar as contribuições dos autores no desenvolvimento do tema e entender suas influências.

\section{Referencial Teórico}

\subsection{Inovação disruptiva}

A noção de inovação disruptiva foi cunhada por Clayton Christensen e Joseph Bower no artigo Disruptive Technologic: catching the wave, publicado em 1995 pela revista Harvard Business Review. Seu conceito inicial está estreitamente vinculado ao efeito das tecnologias disruptivas no mercado como proposta de valor diferenciada daquela disponível anteriormente.

As tecnologias disruptivas, em geral, apresentam um desempenho inferior em relação às estabelecidas nos principais mercados. Em contrapartida, são mais simples, mais baratas, mais confiáveis e, com frequência, mais convenientes de usar. Esses recursos, inicialmente, apresentam baixo desempenho no atributo valorizado pelos clientes principais, mas tem capacidade de romper com o modelo tradicional em que empresas incumbentes ofertam produtos tradicionais (Christensen, 1997; Christensen \& Bower, 1996). Essa perspectiva inicial da disrupção (Christensen, 1997; Christensen et al., 2015) pode facilitar a compreensão da inovação disruptiva como um processo, e não como um produto e/ou serviço em um ponto fixo, mas evoluindo ao longo do tempo (Christensen et al., 2015).

Christensen usou a estrutura de Recursos, Processos e Valores (RPV) para elaborar sua teoria da inovação disruptiva, que descreve como novos participantes com inovações disruptivas ultrapassam gradualmente empresas estabelecidas. A estrutura RPV explica os motivos pelos quais grandes 
empresas conseguem ou falham em responder às descontinuidades do mercado. O ponto crucial é avaliar os pontos fortes (capacidades) organizacionais bem como suas fraquezas (deficiências) em responder às inovações disruptivas (Karimi \& Walter, 2015).

\subsection{Disrupção digital}

A definição da disrupção digital continua sendo um assunto controverso e sem consenso. Contudo, o tema encontra sua base em pesquisas recentes em Sistemas de Informação (SI). Skog et al. (2018, p. 432) propõem que a disrupção digital seja definida como "os processos que se desdobram rapidamente por meio dos quais a inovação digital altera fundamentalmente lógicas historicamente sustentáveis para criação e captura de valor, separando e recombinando vínculos entre recursos ou gerando novos."

Como manifestações específicas da disrupção digital, a digitalização e as plataformas digitais são exemplos específicos de como processos ou artefatos que podem levar à dissolução das principais condições da indústria para organizar a produção e a captura de valor (El Sawy et al., 2010; Karimi \& Walter, 2015). Outros autores também sugerem que a disrupção digital possa ser causada por atores específicos que utilizam tecnologias digitais para minar os modelos estabelecidos de consumo, competição e recursos da indústria (Skog et al., 2018).

A proposta de conceituação do termo por Skog et al.(2018) respalda-se nas seguintes proposições: (1) os processos de disrupção digital tem origem em inovações digitais que rapidamente corroem posições competitivas; (2) eles impactam os ecossistemas de atores geradores de valor, ao quebrar e recombinar os vínculos entre os recursos, facilitando interações e transações mais diretas; e (3) os processos originais de inovação digital são orquestrados por uma ou várias empresas, mas os efeitos na criação e captura de valor são sistêmicos.

\subsection{Capacidades dinâmicas}

O conceito amplamente difundido sobre as capacidades dinâmicas se refere à capacidade de uma empresa de integrar, criar e reconfigurar competências internas e externas para lidar com ambientes em rápida mudança, o que pode ser visto como uma abordagem integradora para entender as novas e inovadoras fontes de vantagem competitiva (Teece et al., 1997). No entanto, Eisenhardt e Martin (2000) discordam dessa compreensão e entendem que a vantagem competitiva é proporcionada pela configuração de recursos e não pelas capacidades (Meirelles \& Camargo, 2014).

Segundo apontam Meirelles e Camargo (2014), a literatura sobre capacidades dinâmicas ressalta a importância de incorporar o papel do dinamismo do ambiente na determinação da vantagem competitiva e, principalmente, como as empresas reagem a esse dinamismo ao longo do tempo (Helfat \& Peteraf, 2003), seja por meio de rotinas (Winter, 2003; Zollo \& Winter, 2002) e processos (Eisenhardt 
\& Martin, 2000; Teece 2007) ou mesmo por outras capacidades (Collis, 1994; El Sawy et al., 2010; Wang \& Ahmed, 2007), pelas quais a organização alcança novas configurações de recursos e capacidades (Helfat et al., 2007).

No entanto, empresas que atuam em ambientes dinâmicos nem sempre possuem capacidades dinâmicas, pois os fundamentos dessas capacidades incluem a capacidade de criar mudanças no mercado e a capacidade de reação às mudanças externas (Meirelles \& Camargo, 2014). O que se sabe é que as capacidades dinâmicas podem responder às inovações disruptivas digitais, pois a identificação das dimensões que criam capacidades dinâmicas tem o potencial de auxiliar a delinear os elementos centrais de transformação digital. Esses delineamentos são necessários para criar recursos e construir capacidade das plataformas digitais, como resposta à disrupção digital (Karimi \& Walter, 2015).

\section{Metodologia}

Este estudo emprega o mapeamento científico, também conhecido como mapeamento bibliométrico, para responder à questão de pesquisa. Este método oferece uma representação de como disciplinas, campos, especialidades e documentos ou autores estão relacionados (Small, 1999). O propósito da pesquisa bibliométrica é identificar tendências, evolução do conhecimento em um determinado campo, avaliar o grau de dispersão e obsolescência de um determinado assunto, medir o impacto das publicações e sua disseminação, quantificar a amplitude de cobertura de determinados periódicos científicos e, identificar a produtividade de autores e instituições (Pritchard, 1969). Para realizar o mapeamento científico, o estudo seguiu as diretrizes propostas por Zupic e Čater (2015), conforme ilustrado na Figura 1.

\section{Figura 1}

Fluxo de trabalho para conduzir o mapeamento científico com métodos bibliométrico

\begin{tabular}{|c|c|c|c|c|}
\hline $\begin{array}{l}\text { Desenho da } \\
\text { pesquisa }\end{array}$ & $\begin{array}{c}\text { Compilação dos } \\
\text { dados bibliométricos }\end{array}$ & Análises & Visualização & Interpretação \\
\hline $\begin{array}{c}\text { Definição da questão } \\
\text { de pesquisa e escolha } \\
\text { do método bibliográfico } \\
\text { adequado }\end{array}$ & $\begin{array}{c}\text { Seleção da base } \\
\text { de dados, filtrar } \\
\text { documentos e } \\
\text { exportar dados }\end{array}$ & $\begin{array}{l}\text { Escolha do } \\
\text { software } \\
\text { bibliométrico }\end{array}$ & $\begin{array}{l}\text { Escolha do } \\
\text { método e } \\
\text { softwares } \\
\text { apropriado }\end{array}$ & $\begin{array}{c}\text { Análises dos } \\
\text { resultados }\end{array}$ \\
\hline
\end{tabular}

Fonte: Modificado de Zupic e Cater (2015).

\subsection{Desenho da pesquisa}

Para entender como está relacionada a pesquisa que vincula a inovação disruptiva digital às capacidades dinâmicas, é necessário compreender como está configurada a base de conhecimento, que inclui os autores influentes e os especialistas; os periódicos com maior impacto; e quais as leituras 
recomendadas sobre o assunto. O método mais apropriado a esse fim é a análise de citação (Citation Analysis), pois é uma medida de influência porque os autores citam documentos que consideram mais importantes para o seu trabalho (Zupic \& Cater, 2015).

Além disso, é importante examinar os pesquisadores centrais e periféricos, a difusão dos conceitos, quais grupos de autores são citados sistematicamente por outro grupo de estudos e as configurações de citações conjuntas. Para esse fim, o método mais adequado é a cocitação (co-citation Analysis) (Zupic \& Cater, 2015; Cobo et al., 2011) porque usa a citação a dois trabalhos para construir medidas de similaridade entre trabalhos citados, autores ou periódicos. Parte do pressuposto de que, quanto mais dois trabalhos são citados juntos, mais seu conteúdo está relacionado. As cocitações também contribuem na deteç̧ão de mudanças de consenso e de paradigmas que podem ocorrer ao longo do tempo (Pasadeos et al., 1998).

\subsection{Compilação dos dados bibliométricos, análise e visualização dos dados}

A pesquisa na base de dados se deu pela associação dos termos "disruptive innov*" or "breaktrough innov*" and "digital" and "dynamic capab*". O objetivo era encontrar trabalhos que abarcassem tanto a inovação disruptiva digital quanto as capacidades dinâmicas.

Existem diversas bases de dados bibliográficos on-line que permitem buscar e recuperar informações em diversos campos científicos (Cobo et al., 2011). Para essa pesquisa, realizada em 17 de junho de 2020, a busca foi feita na base de dados Web of Science (WoS) sobre inovação disruptiva digital e capacidades dinâmicas. A Wos foi escolhida por ser uma das bases mais utilizadas em estudos bibliométricos, porque dispõe de dados suficientes para a maioria das análises bibliométricas (Zupic \& Cater, 2015).

O recorte temporal da pesquisa foi delimitado entre os anos de 1995 até 2019, tendo como ponto de partida a publicação do artigo Disruptive Technologies: Catching the Wave de Clayton M. Christensen que foi o marco inicial para o uso do termo. Com base nos resultados obtidos, foram gerados arquivos contendo os principais dados bibliométrico, que foram posteriormente exportados para análise nas ferramentas Microsoft Excel, Iramuteq e no VOSviewer.

\section{Resultados da pesquisa}

Atendendo aos critérios estabelecidos (Tabela 1), a pesquisa retornou uma amostra de 688 artigos publicados entre o período de 1995 e 2019. A seguir são apresentados os resultados que inclui. (1) a análise descritiva das publicações ao longo do tempo; (2) análise descritiva dos países, idiomas de origem, instituições e periódicos; (3) análise descritiva de citações, referências e autores; (4) análise de palavras, bem como (5) Análise e mapa das cocitações. È importante ressaltar que, devido ao dinamismo da base de dados, é possível que pesquisas em períodos posteriores apresentem resultados distintos. 


\section{Tabela 1}

Critérios da Pesquisa na Base WOS

\begin{tabular}{ll}
\hline \hline \multicolumn{1}{c}{ Item } & \multicolumn{1}{c}{ Conteúdo } \\
\hline \hline Banco de dados pesquisado & Principal Coleção do Web of Science \\
Índices de citações & SCI-EXPANDED, SSCI, A\&HCI, CPCI-S, CPCI-SSH, ESCI. \\
Termos da Pesquisa & TÓPICO: ("disruptive innov*") OR TÓPICO: ("breaktrough innov*") AND \\
& TÓPICO: ("*digital*") AND TÓPICO: ("Dynamic Capab*") \\
Tipo de documento & ARTICLE OR REVIEW \\
Período da busca & $1995-2019$ \\
\hline \hline
\end{tabular}

\subsection{Análise descritiva das publicações científicas ao longo do tempo}

O número de artigos publicados é um importante indicador dos resultados do conhecimento científico, das contribuições da pesquisa e do nível de desenvolvimento do campo (Shang et al., 2019). A Figura 2 apresenta a distribuição temporal da produção científica que aponta as conexões entre os trabalhos que contemplam a inovação disruptiva digital e capacidades dinâmicas produzidas ao longo do tempo.

É importante mencionar que o termo "tecnologia disruptiva" foi cunhado por Clayton Christensen por meio da publicação do artigo Disruptive Technologic: cathing the wave, em 1995, em co-autoria com Joseph Bower. Em 1997, ao lançar o livro The Innovator's Dilemma, Christensen passou a adotar o termo inovação disruptiva. Desde então, essa obra é considerada uma de suas obras mais conhecidas e influentes, ajudando a popularizar a inovação disruptiva. A partir das suas publicações, diversos estudos se sobre o assunto, e como um campo novo de pesquisa, a tendência é que muitos esforços fossem empreendidos para construir conexões com outras áreas da ciência. 
Figura 2

Evolução das Publicações no campo da pesquisa no período entre 2000 e 2019

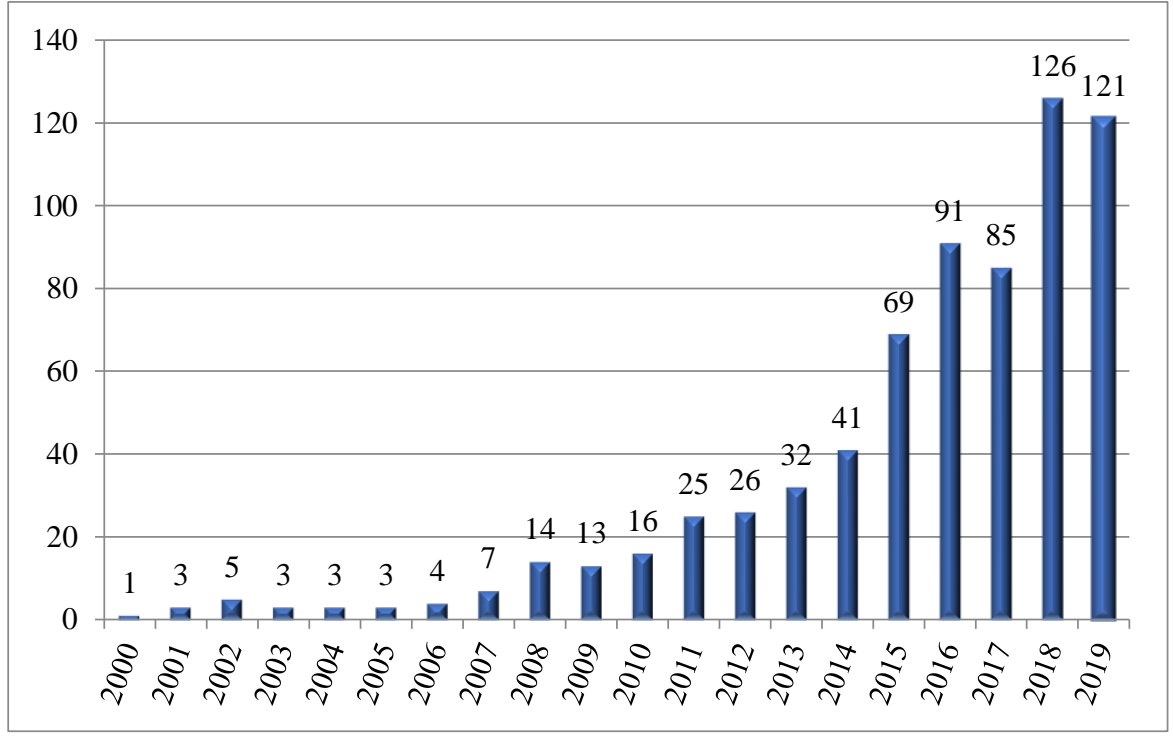

Fonte: Dados da pesquisa (2020).

A primeira publicação que apareceu na base dados Wos, contemplando os termos de pesquisa utilizados, foi em 2000, com o título “Will Disruptive innovations cure health care?” que recebeu o total de 270 citações, desde 2001. O artigo, escrito por Clayton Christensen, Richard Bohmer e Jonh Kenagy, abordou as vantagens das inovações disruptivas nos sistemas de saúde, particularmente nos EUA, abordando a permissão de procedimentos médicos executados em ambientes mais baratos e convenientes, tornando os cuidados com a saúde mais eficientes e ampliando o acesso de mais pacientes a mais procedimentos

Entre os anos 2000 e 2007 foram publicados apenas 29 artigos, com uma média de 4,14 ao ano. Somente a partir de 2015 percebe-se um avanço considerável, sendo que o ano de 2018 foi o que apresentou o maior número de publicações, com 126 trabalhos. O estudo mais relevante deste período, em termos de citações recebidas (98 citações até 2019) foi “Why Tourists Choose Airbnb: a MotivationBased Segmentation Study" de Daniel Guttentag, Stephen Smith, Luke Potwarka, Luke e Mark Havitz. Publicado em 2015, este estudo investigou as motivações dos turistas para usar o Airbnb, indicando que os entrevistados foram fortemente atraídos pelo Airbnb por seus atributos práticos, e em menor medida, por seus atributos experimentais.

\subsection{Análise descritiva dos países, idiomas de origem, instituições e periódicos}

Os países ou regiões considerados mais influentes são aqueles que tem mais autores, afiliados ou oriundos, interessados no tema. A amostra retornou 69 países ou regiões. Desse total, o país com maior representatividade são os EUA, com 259 (37,65\%) de autores envolvidos com a temática, 
seguidos pela Inglaterra com 91(13,23\%). A língua predominante nos estudos é a língua inglesa, que aparece em $95,93 \%$ das publicações, seguida pelo espanhol, presente em $14 \%$ e o português em $8 \%$. Dentre os registros encontrados, em 11 (1,60\%) não havia informações a respeito dos dados no campo analisado.

O referencial teórico está distribuído em 460 periódicos que publicaram 688 artigos, a maioria com apenas 1 ou duas publicações. A Tabela 2 mostra os 10 periódicos com maior número de publicações, que podem ser considerados de alto rendimento, pois, segundo Shang, et al. (2019), revistas que publicam mais de oito artigos são assim consideradas.

\section{Tabela 2}

Principais Periódicos por Número de Artigos Indexadas no Campo da Pesquisa no Período entre 2000 e 2019

\begin{tabular}{lcccccc}
\hline \hline \multicolumn{1}{c}{ Título da fonte } & $\begin{array}{c}1995 \text { a } \\
2004\end{array}$ & $\begin{array}{c}2005 \text { a } \\
\text { 2014 }\end{array}$ & $\begin{array}{c}2015 \text { a } \\
2019\end{array}$ & Total & JCR (2019) \\
\hline \hline Technological Forecasting and Social Change & 0 & 3 & 21 & 24 & 5.846 \\
Technology Analysis \& Strategic Management & 0 & 5 & 9 & 14 & 1.867 \\
Journal of Product Innovation Management & 0 & 8 & 3 & 11 & 5.000 \\
Energy Research \& Social Science & 0 & 0 & 10 & 10 & 4.771 \\
Research Technology Management & 1 & 9 & 0 & 10 & 2.449 \\
Harvard Business Review & 4 & 4 & 1 & 9 & 5.700 \\
Sustainability & 0 & 0 & 9 & 9 & 2.576 \\
Research Policy & 0 & 5 & 3 & 8 & 5.351 \\
Technovation & 0 & 5 & 3 & 8 & 5.729 \\
International Journal of Information Management & 0 & 3 & 4 & 7 & 8.210 \\
\hline \hline
\end{tabular}

O total das publicações nos periódicos corresponde a, aproximadamente, $16 \%$ de todo o acervo pesquisado. Dois periódicos merecem destaque: o Technological Forescasting and Social Change e o Technology Analysis Strategic Management. Além desses, as publicações nos periódicos Energy Research \& Social Science e Sustainability cresceram nos últimos cinco anos, tornando-se fontes importantes de informações para os pesquisadores. 


\section{Tabela 3}

Principais Periódicos por Número de Citações no Campo da Pesquisa no Período entre 2000 e 2019

\begin{tabular}{lc}
\hline \hline \multicolumn{1}{c}{ Título da fonte } & Citações \\
\hline \hline Harvard Business Review & 2.469 \\
Research Policy & 480 \\
Technological Forecasting and Social Change & 374 \\
Technovation & 344 \\
Journal of Product Innovation Management & 335 \\
Research Technology Management & 327 \\
International Journal of Information Management & 278 \\
Health Affair & 236 \\
Journal of Cleaner Production & 191 \\
Energy Research \& Social Science & 114 \\
\hline \hline
\end{tabular}

Ao analisar a quantidade de citações das publicações (Tabela 3) o ranking dos periódicos apresenta uma configuração diferente, tendo a Harvard Business Review como o mais citado. Esse resultado deve-se, principalmente, ao fato de que os trabalhos de Christensen, considerado o autor mais proeminente na área, estão concentrados nessa revista. Além disso, dentre os artigos mais citados (Tabela 4) cinco foram publicados nessa revista. Em segundo lugar, está o Research Policy que é "geralmente reconhecida como a principal revista na área de estudos sobre inovação", segundo a própria Elsevier.

\subsection{Análise descritiva de citações, referências e autores}

Os artigos que compõem a amostra receberam 11.397 citações no período investigado dando uma média de 16,56 citações por artigo. A Figura 3 mostra como se deu a evolução no período. 


\section{Figura 3}

Evolução das Citações no Campo Pesquisado entre o Período de 2000 e 2019

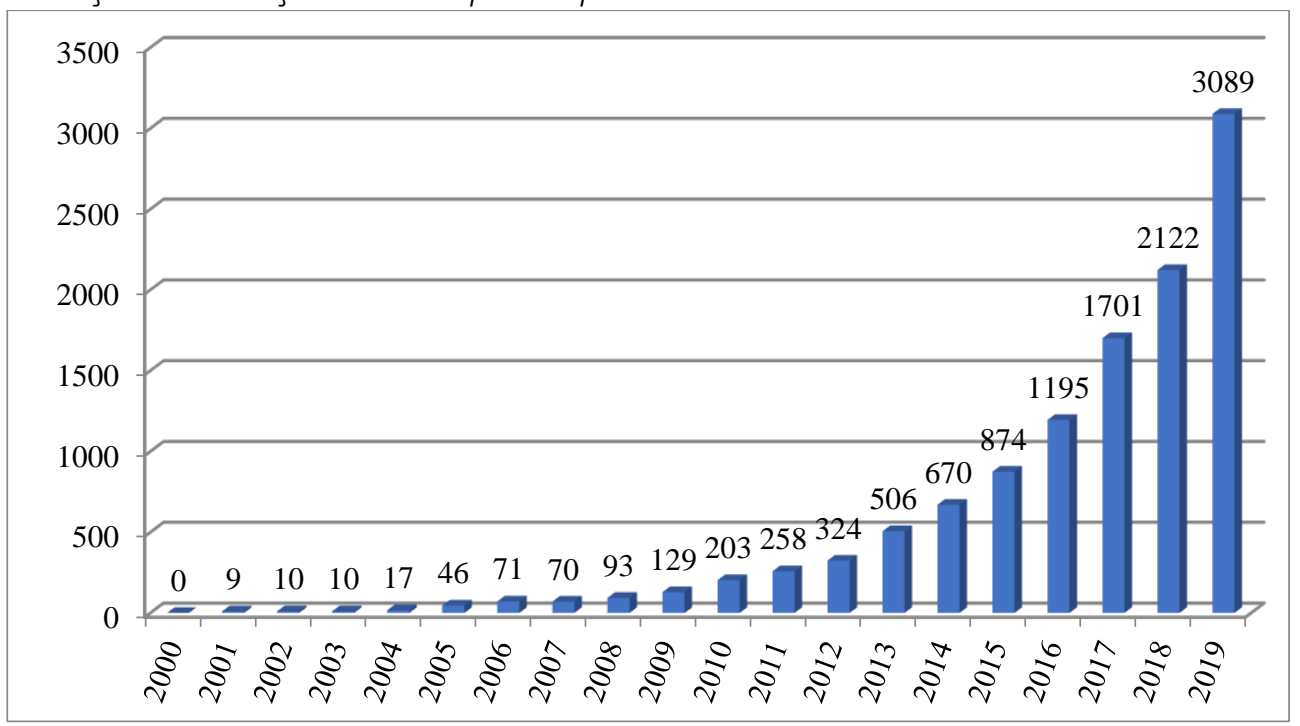

Fonte: Dados da pesquisa (2020).

As primeiras citações que aparecem no ano de 2001 e 2002 são referentes também ao trabalho de Clayton Christensen, Richard Bohmer e Jonh Kenagy, "Will Disruptive innovations cure health care". Nota-se que a evolução das citações seguiu uma tendência semelhante às das publicações, evidenciando um acentuado interesse no tema.

No que diz respeito às referências mais citadas, foi feito um recorte, a critério do pesquisador, daquelas que tiveram mais de 150 citações, resultando em 11 artigos que concentram 30,05\% do total da amostra.

Conforme a Tabela 4, o trabalho de O'Reilly e Tushmann (2004) é o mais citado, com 833 citações. O artigo discute os desafios e conflitos gerenciais relacionados a capitalizar as fontes tradicionais de receita em comparação a explorar oportunidades de inovações novas e radicais. É importante destacar que empresas bem-sucedidas são hábeis em refinar suas ofertas atuais, mas enfrentam dificuldades quando se trata de ser pioneiro em desenvolvimento de produtos e serviços radicalmente inovadores. Esse tema tem sido objeto de intensos debates no campo da gestão empresarial. 
Tabela 4

Artigos com Maior Número de Citações na Amostra no Campo Conceitual entre 1995 e 2019

\begin{tabular}{|c|c|c|c|}
\hline & $\begin{array}{l}\text { Total de } \\
\text { citações }\end{array}$ & Artigo & \% citações \\
\hline 1 & 833 & $\begin{array}{l}\text { O'Reilly III, C. A., Tushman, M. L. (2004). The ambidextrous organization. Harvard } \\
\text { Business Review, 82(4), 74-81. }\end{array}$ & $7,31 \%$ \\
\hline 2 & 697 & $\begin{array}{l}\text { Johnson, M. W., Christensen, C. M., \& Kagermann, H. (2008). Reinventing your } \\
\text { business model. Harvard Business Review, 86(12), 50-59. }\end{array}$ & $6,12 \%$ \\
\hline 3 & 388 & $\begin{array}{l}\text { Guttentag, D. (2015). Airbnb: Disruptive innovation and the rise of an informal } \\
\text { tourism accommodation sector. Current Issues in Tourism, 18(12), 1192-1217. }\end{array}$ & $3,40 \%$ \\
\hline 4 & 267 & $\begin{array}{l}\text { Christensen, C. M., Bohmer, R., \& Kenagy, J. (2000). Will disruptive innovations cure } \\
\text { healthcare? Harvard Business Review.78(September-October), 102-111. }\end{array}$ & $2,34 \%$ \\
\hline 5 & 229 & $\begin{array}{l}\text { Heerema, S. J., \& Dekker, C. (2016). Graphene nanodevices for DNA sequencing. Nat. } \\
\text { Nanotechnol, 11, 127- } 136 .\end{array}$ & $2,01 \%$ \\
\hline 6 & 210 & $\begin{array}{l}\text { Christensen, C. M., Baumann, H., Ruggles, R. \& Sadtler, T. M. (2006). Disruptive } \\
\text { innovation for social change. Harvard Business Review 84, 94-101. }\end{array}$ & $1,84 \%$ \\
\hline 7 & 165 & $\begin{array}{l}\text { Christensen, C. M., Raynor, M. E., Rory, M., \& McDonald, R. (2015). What is } \\
\text { disruptive innovation? Harvard Business Review, 93(12), 44-53. }\end{array}$ & $1,45 \%$ \\
\hline 8 & 164 & $\begin{array}{l}\text { Kivimaa, P., Kern, F., (2016). Creative destruction or mere niche support? Innovation } \\
\text { policy mixes for sustainability transitions. Research Policy, 45(1), 205-217. }\end{array}$ & $1,44 \%$ \\
\hline 9 & 161 & $\begin{array}{l}\text { Hwang, J., \& Christensen, C. M. (2008). Disruptive innovation in health care delivery: } \\
\text { a framework for business model innovation. Health Affairs, 27(5), 1329-1335. }\end{array}$ & $1,41 \%$ \\
\hline 10 & 161 & $\begin{array}{l}\text { Haitz, R., \& Tsao, J. Y. (2011). Solid-state lighting: the case } 10 \text { years after the } \\
\text { prospects. Phys. Status Solidi, 208(1), 17-29. }\end{array}$ & $1,41 \%$ \\
\hline 11 & 150 & $\begin{array}{l}\text { Tulevski, G. S., Franklin, A. D., Frank, D., Lobez, J. M., Cao, Q., Park, H. Afzali, A., Han, } \\
\text { S.-J., Hannon, ,J. B., \& Haensch, W. (2014). Toward high-performance digital logic } \\
\text { technology with carbonnanotubes. ACS Nano, 8(9), 8730-8745. }\end{array}$ & $1,32 \%$ \\
\hline
\end{tabular}

A partir da análise das principais inovações, na década de 2000, o trabalho de Kagermann e Christensen (2008) - o segundo mais citado com 97 registros - indica que poucas empresas estavam focadas no desenvolvimento de novos modelos de negócios. No entanto, muitos executivos acreditavam que a inovação do modelo de negócios seria ainda mais importante para o sucesso do que a inovação de produtos ou serviços. No entanto, esses executivos se questionaram sobre a dificuldade em gerar crescimento a partir de novos modelos de negócio. Os autores sugeriram a existência de dois problemas: a falta de definição pela escassez de estudo formal sobre a dinâmica e os processos de desenvolvimento de modelos de negócios, e que poucas empresas entendem bem seu modelo de negócios atual.

A Tabela 5 mostra o nível de produtividade dos autores que tiveram o maior número de citações, a quantidade de registros na amostra, bem como os registros em que os autores configuram como autor principal. A análise da produção dos autores é relevante para compreender quem tem pesquisado sobre o tema e como contribuíram para a evolução do campo. 


\section{Tabela 5}

Lista dos Dez Autores com Maior Número de Citações e Registros na Amostra

\begin{tabular}{clclcc}
\hline \hline \multicolumn{1}{c}{ Autoridades na área } & Citações & $\begin{array}{c}\text { Autores de alto } \\
\text { rendimento }\end{array}$ & Registros & $\begin{array}{c}\text { Autor } \\
\text { principal }\end{array}$ \\
\hline \hline 1 & CHRISTENSEN, C. M. & 1729 & CHRISTENSEN, C. M. & 8 & 6 \\
2 & HANG, C. C. & 307 & HANG, C. C. & 5 & 2 \\
3 & SULTAN, N. & 168 & SULTAN, N. & 4 & 4 \\
4 & ANSARI, S. & 143 & GURTNER, S. & 4 & 0 \\
5 & GURTNER, S. & 59 & REINHARDT, R. & 4 & 4 \\
6 & REINHARDT, R. & 59 & FLAVIN, M. & 4 & 4 \\
7 & CHEN, J. & 34 & SANDSTROM, C. & 4 & 2 \\
8 & FLAVIN, M. & 33 & ANANG, Q. P. & 4 & 0 \\
9 & SANDSTROM, S. & 9 & CHEN, J. & 3 & 2 \\
10 & ZHANG, Q. P. & & & 3 & 2 \\
\hline \hline
\end{tabular}

Entre os 1825 autores da amostra, 10 deles concentram cerca de 22,8\% do total de citações. Dentre eles, destaca-se o professor Clayton Christensen com o índice de citação dos mais altos. Aparece com 8 trabalhos publicados na área, figurando como autor principal em 6 deles. Ele ficou conhecido por seus estudos sobre inovação disruptiva, tendo lecionado Administração na Harvad Business School (HBS). Ao analisar os dados gerais ancorados na WoS constam 71 publicações de sua autoria com 6.787 citações em 5.645 trabalhos. $O$ ano em que as suas obras foram mais citadas foi 2018 com 675 citações e 2019 com 687.

Outro autor de destaque é o professor Chang-Chieh Hang do Department Industrial Systems Engineering \& Management na National University of Singapore e Diretor Executivo no Institute for Engineering Leadership. O seu trabalho mais conhecido é A reflective review of disruptive 159nnovation theory. Na Coleção principal do WoS constam 108 publicações de sua autoria que somam 4.088 citações por 3.360 trabalhos.

\subsection{Análises de termos e palavras-chave}

A análise das palavras-chave (Figura 4) permite identificar a frequência dos termos utilizados nos documentos, sendo um indicativo de estudos e ideias discutidas no campo. Com o apoio do software VOSviewer foi formada uma "nuvem" de palavras a partir daquelas que aparecem nos títulos, resumos e palavras-chave dos artigos. Um dos critérios estabelecidos foi a ocorrência das palavras pelo menos 5 vezes, tendo sido encontrados 168 corpus textuais. 
Figura 4

Palavras-chave mais frequentes elaborado pelo VOSviewer

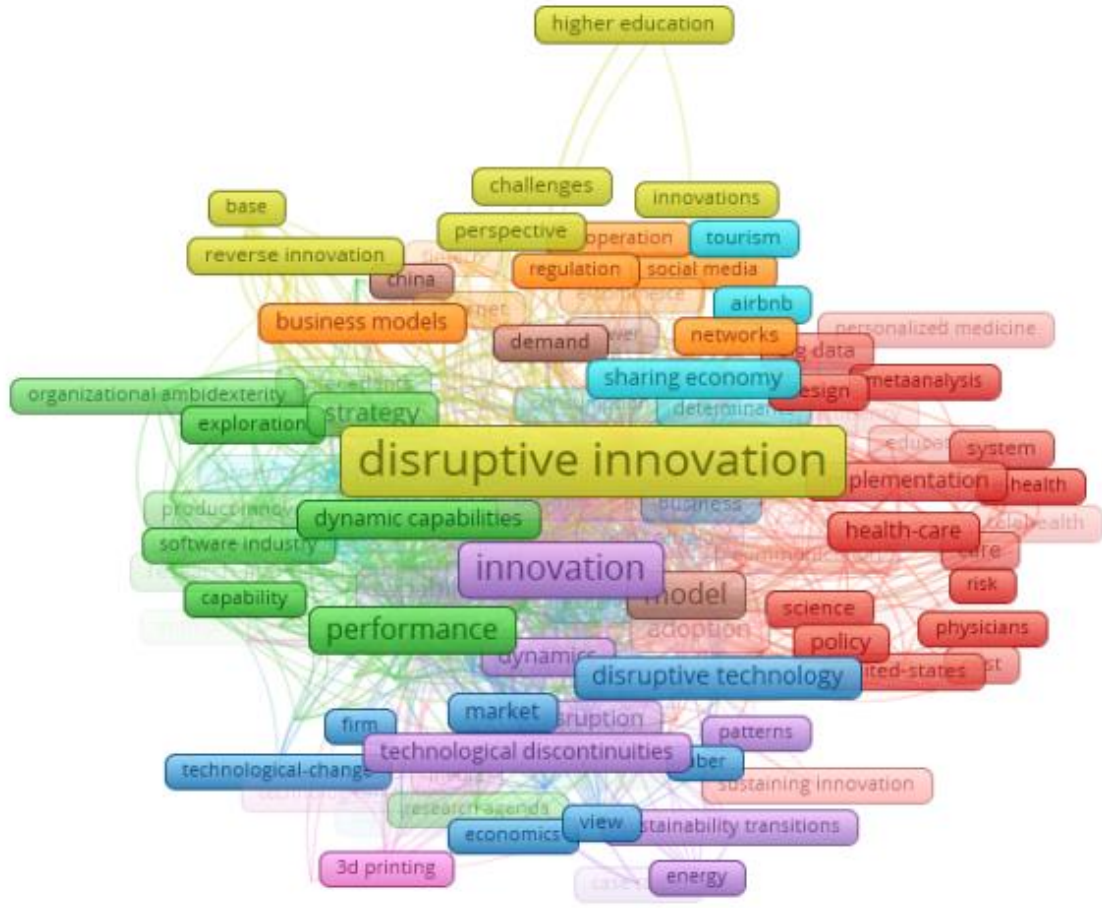

Fonte: Dados da pesquisa (2020).

O termo diruptive Innovation é o mais frequente, com 282 ocorrências, 164 links e 1053 links strenghts. O segundo lugar, o termo innovation aparece 111 vezes, com 132 links e 453 link strenght. O termo digital, apesar de compor os critérios de busca da pesquisa, não aparece em nenhuma ocorrência.

A pesquisa resultou na formação de 10 clusters, sendo o maior deles com 41 termos, que se referem a Health-care, Physicians, e-health, telehealth, personlized medicine, therapy que indicam estudos relativos à área da saúde. O segundo maior cluster, composto por 29 itens, aparecem os termos que tratam de estratégia, incluindo o termo da pesquisa dynamic capabilities. Além disso, foram encontrados termos como strategy, capability, absorptive-capacity, exploration, exploitation, organizational ambidexterity, product innovation, resource-based view. Finalmente, o terceiro maior cluster, com 17 itens, aborda mudanças radicais e tecnológicas, com os termos disruptive technologies, disruptive innovations, technological-change, technological-innovations e radical innovation.

É importante ressaltar que a centralidade do termo disruptive innovation indica que ele tem maior representatividade no conjunto. 


\subsection{Análise das cocitações de referências}

Além de analisar os artigos e autores mais citados, este trabalho, também realizou a análise de cocitação, gerada com o uso do software VOSviewer por meio do método de contagem completa, cocitation, cited references. Após cruzar os dados de 30.979 referências, foram selecionados 49 itens. Foram retiradas as referências que tratavam sobre metodologia por não contribuírem para a análise do campo pesquisado, resultando 47 itens. A Figura 5 mostra uma rede de cocitação, processada a partir dessas referências, identificando 4 clusters caracterizados por cores.

A obra de Christensen (1997) ocupa uma posição centralizada na rede de cocitação, evidenciando que é uma referência na área inovação disruptiva. O posicionamento centralizado do cluster ao qual ele pertence permite compreender que ele contribui como seminal para diversas áreas.

Figura 5

Rede de cocitação das referências elaborado pelo vosviewer

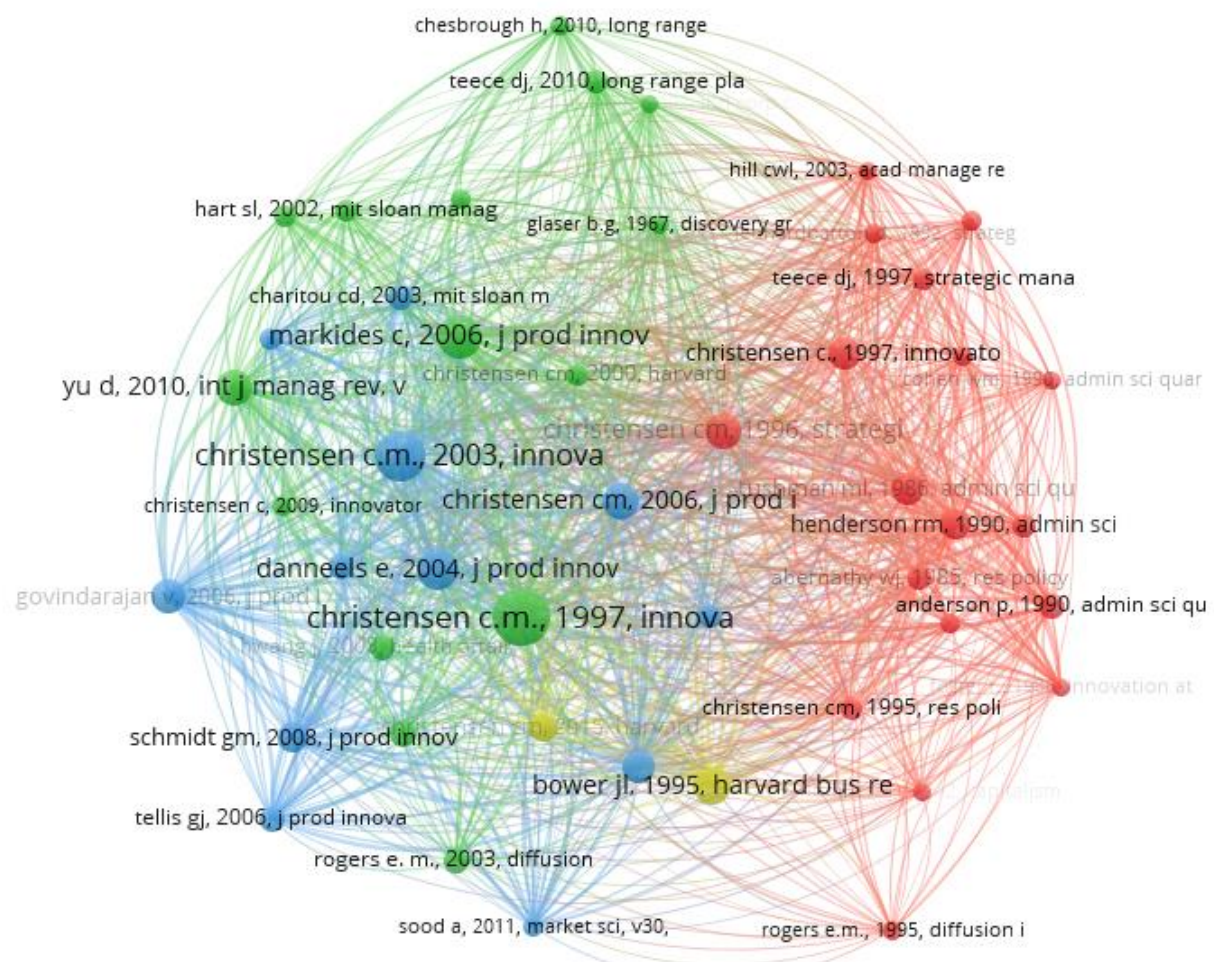

Fonte: Dados da pesquisa (2020).

\subsubsection{Cluster 1: Firma (vermelho)}

O primeiro cluster, denominado "firma", é composto por 18 referências e recebeu esse nome por ser a palavra com maior incidência e maior representatividade entre os artigos, conforme sinalizado pelo software Iramuteq (Figura 6) a partir da análise de similitude. A Análise de similitude é baseada na 
teoria dos grafos e representa a ligação entre palavras do corpus textual. A partir dessa análise é possível inferir a estrutura de construção do texto e os temas de relativa importância, a partir da co-ocorrência entre as palavras (Salviati, 2017).

As referências que se destacam neste cluster, por apresentarem maior valor de total de links strenght são Christensen e Bower (1996), Tushman e Anderson (1986) e Henderson e Clark (1990).

\section{Figura 6}

Similitudes via Iramuteq para o cluster 1

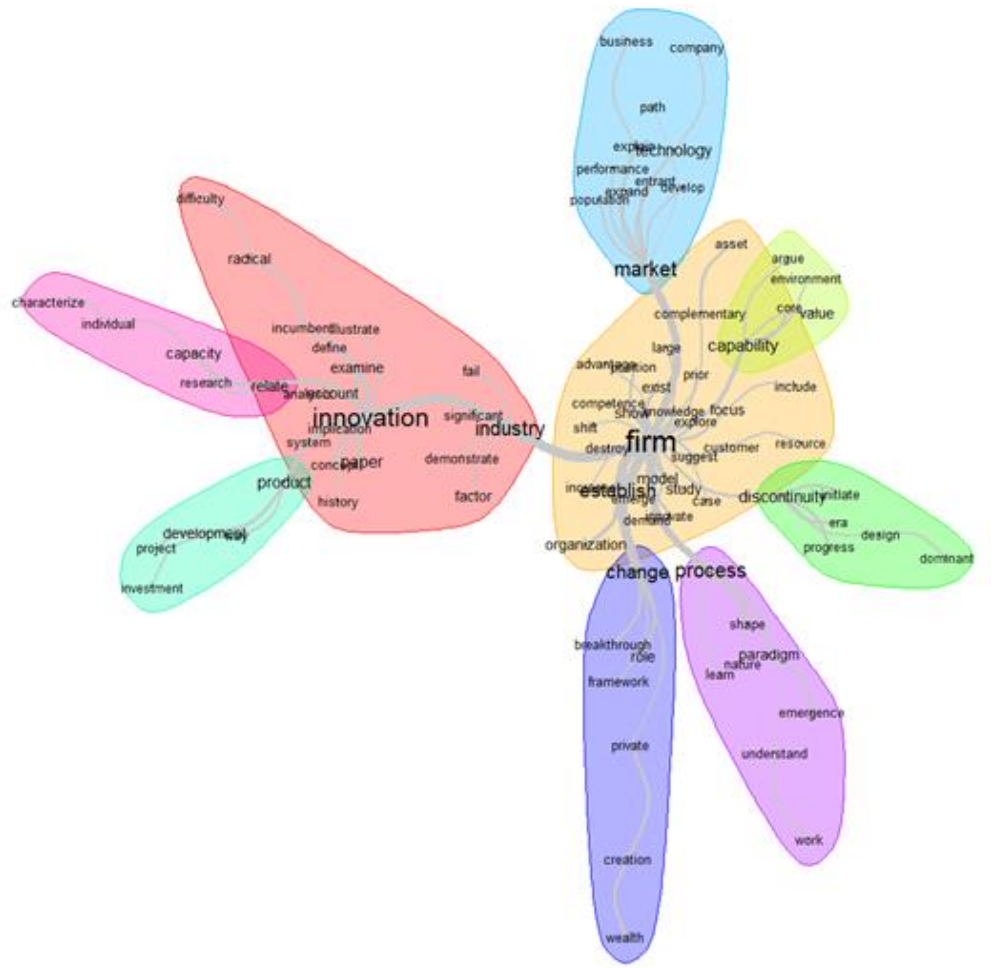

Fonte: Dados da pesquisa (2020).

Christensen e Bower (1996) propõem uma reflexão sobre como as empresas líderes de mercado são, em alguns casos, surpreendidas e perdem sua posição de liderança para empresas menores e com menos capacidade de investimento e controle de mercado. Eles concluem que, a principal razão pela qual essas empresas perdem suas posições de liderança no setor quando confrontadas com certas categorias de mudanças tecnológicas, tem pouco a ver com a própria tecnologia - com seu grau de novidade ou dificuldade - em relação às habilidades e experiência da empresa. Pelo contrário, fracassam porque ouvem com muita atenção seus clientes e os clientes impõem limites estritos às estratégias que as empresas podem seguir. Além disso, uma premissa fundamental do trabalho é que os padrões de alocação de recursos influenciam fortemente os tipos de inovações nas quais as principais empresas terão sucesso ou fracassarão. 
O trabalho de Tushman e Anderson (1986) se concentra em analisar os padrões de mudança tecnológica e no impacto das descontinuidades tecnológicas nas condições ambientais. Eles demonstram que a tecnologia evolui de mudanças incrementais pontuadas por mudanças radicais que destroem a competência das indústrias, causando incerteza ambiental e munificência. Abernathy e Clark (1985) pontuam que as grandes mudanças tecnológicas podem ser classificadas como competence-destroying e competence-enhancing porque destroem ou aprimoram a competência das empresas existentes em um setor. Tushman e Anderson (1986) enfatizam que, apesar das competencedestroying iniciarem por empresas entrantes no mercado e estejam relacionadas ao aumento da turbulência ambiental, as descontinuidades do tipo competence-enhancing são iniciadas pelas empresas existentes e estão associadas à diminuição da turbulência ambiental. As empresas que iniciam grandes mudanças tecnológicas crescem mais rapidamente do que outras empresas.

Henderson e Clark (1990) demonstram que a categorização tradicional da inovação em incremental e radical é incompleta. Eles examinaram inovações que trouxeram melhorias aparentemente menores nos produtos tecnológicos e, distinguindo entre os componentes de um produto e a maneira como elas são integradas ao sistema, definiram "arquitetura" do produto como inovações que alteram a arquitetura de um produto sem alterar seus componentes. Essas inovações do tipo arquitetônicas apresentam às organizações estabelecidas desafios sutis que podem ter implicações competitivas significativas. Para os autores, as inovações podem ser de diferentes tipos e com efeitos competitivos diversos.

Como parte desse cluster, estão também os trabalhos que tratam sobre capacidades dinâmicas (Teece et al., 1997), core capabilities (Leonard-Barton,1992; Tripsas \& Gavetti, 2000) e capacidades absortivas (Cohen, 1990).

Dessa forma, o cluster 1 tem em comum temas que analisam as categorias de inovações, a intensidade e implicações para as firmas, relacionando as capacidades dinâmicas.

\subsubsection{Cluster 2: Inovação (verde)}

O cluster 2 é caracterizado pela presença de 15 componentes relacionados ao tema "inovação". Por ser a palavra mais frequente, pode representar melhor o conjunto dos artigos que o compõem, conforme sinaliza a Figura 7 gerada pelo software Iramuteq, a partir da análise de similitude. Destacamse os trabalhos de Christensen (1997), Markides (2006) e Yu e Hang (2010). 
Figura 7

Similitudes via Iramuteq para o cluster 2

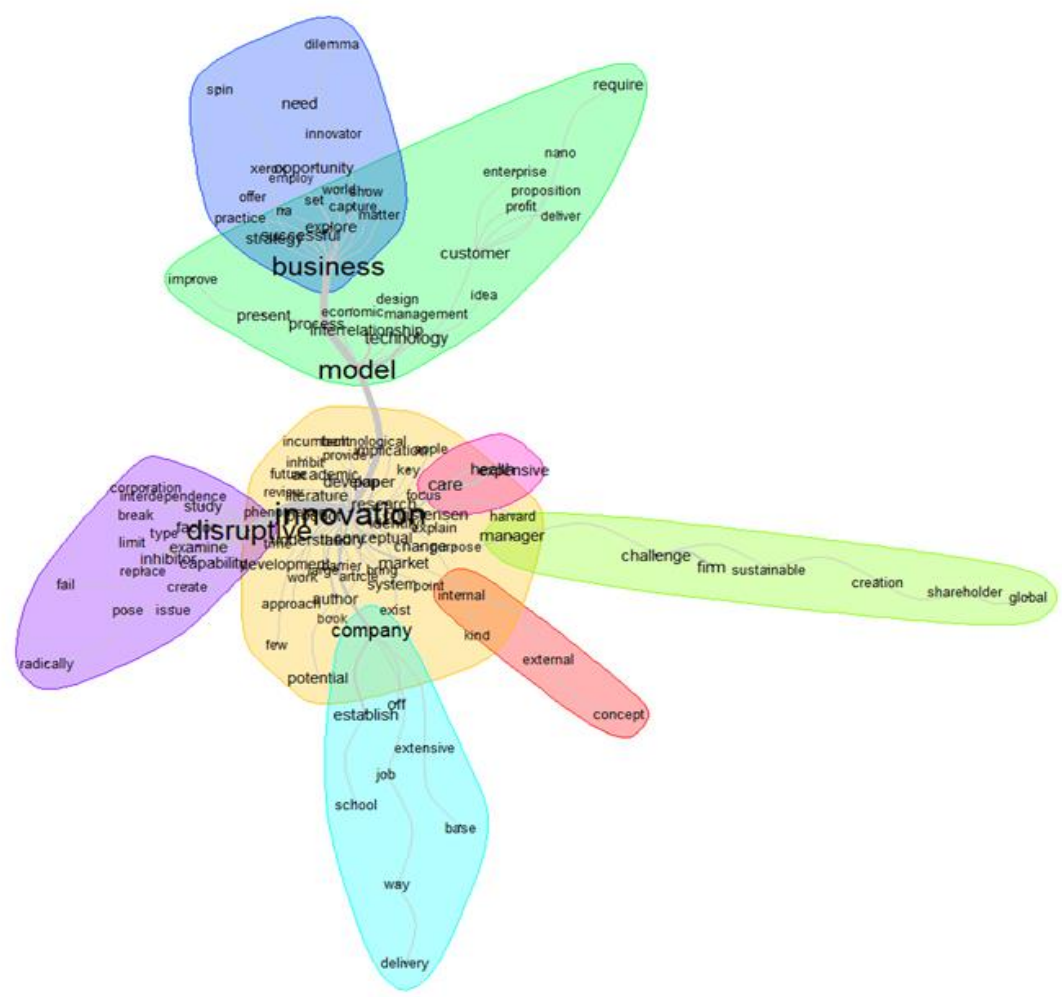

Fonte: Dados da pesquisa (2020).

Em seu trabalho de 1997, Christensen confirma as ideias levantadas no artigo anterior de 1996, especialmente no que diz respeito às inovações tecnológicas e aos motivos pelos quais novas tecnologias superam as existentes no mercado. Ele usa as lições dos sucessos e fracassos de empresas líderes e entrega um conjunto de princípios para capitalizar o fenômeno da inovação disruptiva. Esses princípios auxiliam na definição de quando é apropriado ouvir os clientes, quando investir em desenvolvimento de novos produtos de desempenho inferior com margens mais baixas e quando buscar mercados pequenos à custa de, aparentemente, maiores lucros.

Markides (2006) compila, o que a literatura acadêmica diz sobre duas categorias específicas de inovações disruptivas, as inovações em modelos de negócios e as inovações radicais em produtos. Demonstrou que essas categorias de inovação representam desafios bastante diferentes para empresas estabelecidas, com implicações radicalmente diferentes para os gerentes. Conclui afirmando que as inovações disruptivas não são iguais e propõe que sejam categorizadas com mais precisão. Particularmente, pede que as inovações tecnológicas, de modelo de negócios e de produtos novos sejam tratadas como fenômenos distintos. A justificativa é que todos os três tipos de inovação podem seguir um processo semelhante para invadir mercados existentes e ter efeitos igualmente disruptivos 
nas empresas incumbentes, mas no final do dia produzem diferentes mercados com implicações gerenciais diferentes. Ainda enfatiza, que somente quando o assunto inovação disruptiva é dividido nessas categorias mais refinadas, pode progredir (Markides, 2006).

O objetivo de Yu e Hang (2010) foi revisar e refletir sobre o tema da inovação disruptiva. Eles visaram esclarecer o conceito de inovação disruptiva e identificar mal-comuns, bem como avaliar os desenvolvimentos teóricos e empíricos no campo para identificar lacunas de pesquisa que precisariam ser abordadas no futuro. Os autores propuseram uma série de potenciais inibidores e facilitadores de inovações disruptivas como considerações gerenciais.

No geral, esse conjunto de trabalhos converge para refletir sobre inovação disruptiva, abordando conceitos, análises críticas e categorizações.

\subsubsection{Cluster 3: Disrupção}

Um grupo de palavras, composto por "innovation" (39 vezes), "disruptive" (37) e "technology" (36) surge com frequência dos corpus textuais (Figura 8). Considerando que o cluster anterior foi denominado como "inovação", foi decidido que esse novo conjunto seria designado disrupção. Este cluster é composto por 12 itens, com destaque para os trabalhos de Christensen e Raynor (2003) e Danneels, (2004) na análise feita no VOSviewer.

\section{Figura 8}

Similitudes via Iramuteq para o cluster 3

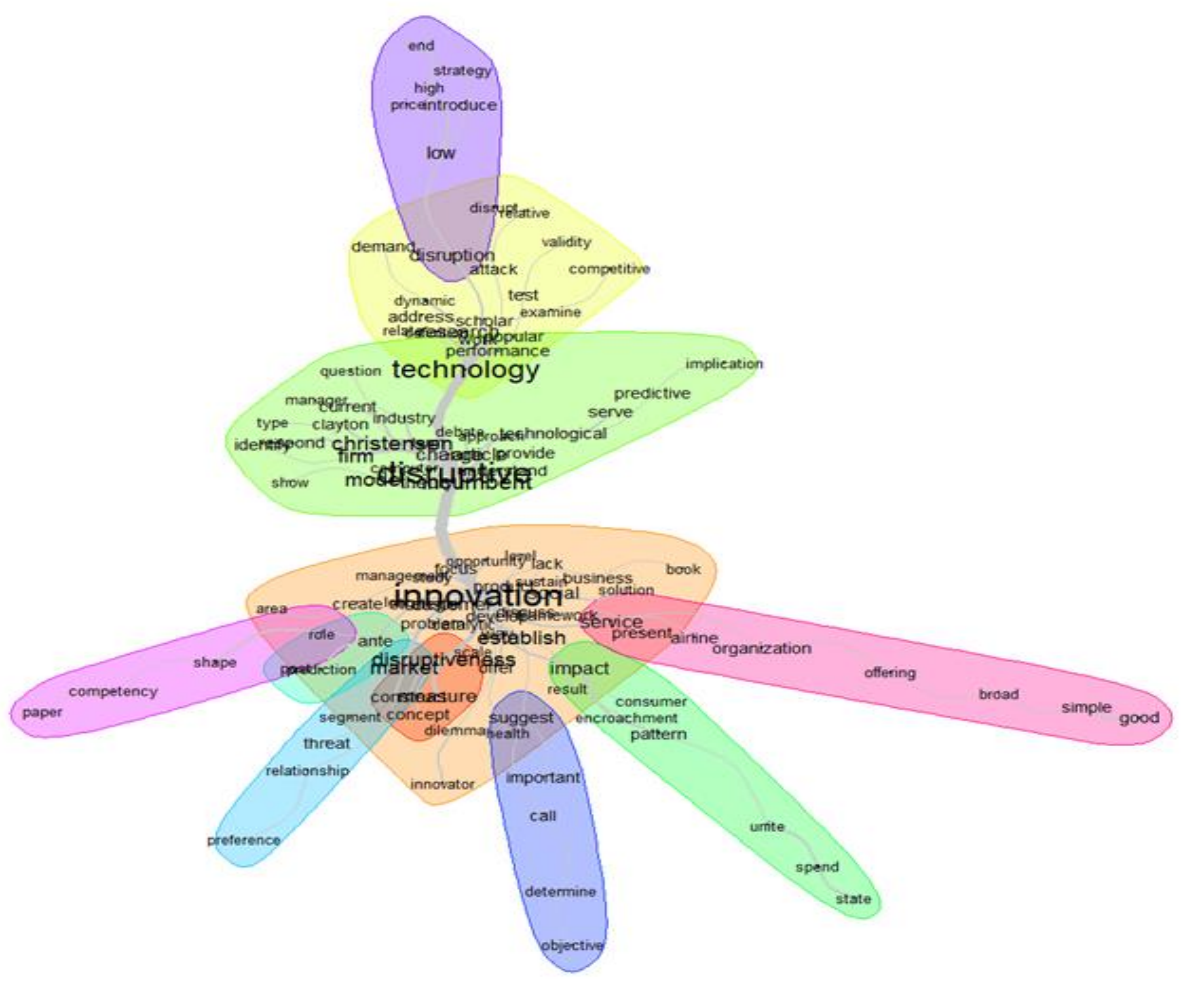


O trabalho de Christensen e Raynor (2003) é considerado um clássico, pois os autores expandem a ideia de disrupção apontando como essa ela permanece oportuna e relevante no ambiente de negócios. Os autores identificam as forças que levam os gerentes a tomarem más decisões à medida que vão moldando novas ideias. Eles oferecem também estruturas para criar as condições adequadas para uma disrupção bem-sucedida.

Danneels (2004) apresentou um reexame sobre o campo da inovação disruptiva, com base nos trabalhos de Christensen, por entender que muitas questões ainda precisavam ser respondidas. Ele conduziu uma investigação sistemática adicional no campo, revisitando cuidadosamente a noção de mudança tecnológica disruptiva, seus mecanismos e suas consequências para empresas e indústrias. Sua conclusão confirma que muitas questões ainda permaneciam sem solução e que os estudiosos precisariam desenvolver uma classificação de tecnologias para entender como novas tecnologias, ao surgirem, poderiam moldar o destino de empresas e indústrias. Além disso, destacou a importância de aumentar o mérito teórico e gerencial da teoria, desenvolver previsões e testar quais tecnologias se tornarão disruptivas e quais empresas sucumbirão, em contrapartida, às que prosperarão com o seu surgimento (Danneels, 2004).

Apesar da rede ter formado o cluster 4, ele foi excluído da análise por conter apenas dois autores e, portanto, não ser representativo o suficiente.

\section{Conclusões}

Com base nos registros disponíveis no banco de dados da WOS no período de 1995 a 2019, bem como na análise de citações e cocitações relacionadas à inovação disruptiva digital e capacidades dinâmicas, pode-se concluir que há um avanço progressivo do conhecimento nessa área. Esse progresso é evidenciado, pelo aumento do número de publicações e citações ao longo dos anos, indicando um interesse crescente neste campo de estudo, portanto, a necessidade de continuar explorando suas possibilidades.

Entre os periódicos mais importantes e com maiores incidências de publicações no período de 2015 a 2019, destacam-se o Technological Forecasting and Social Chang, o Technology Analysis \& Strategic Management, Energy Research \& Social Science e o Sustainability. Essa informação é útil para pesquisadores, pois permite descobrir pesquisas relevantes e selecionar periódicos apropriados para seus próprios trabalhos.

Quanto às citações, o periódico Harvard Business Review encontra-se numa posição à frente dos outros. Esse periódico abrange diversas áreas do conhecimento como negócios, gestão, tecnologia, inovação, gestão da informação e saúde. Isso evidencia que a inovação disruptiva continua sendo um tema abrangente, envolvendo diversas áreas de conhecimento e oferecendo um vasto campo para 
pesquisas futuras. Com base nessas informações, os pesquisadores podem avaliar quais periódicos são mais adequados para publicar seus trabalhos e maior visibilidade.

As redes de coautoria permitiram identificar 4 clusters a partir da associação de termos encontrados nos títulos dos trabalhos, resumos e palavras-chave, cada um abordando uma temática específica. O cluster 1 aborda o papel das inovações, configurações, intensidade e implicações para as firmas e concentra trabalhos que relacionam as capacidades dinâmicas, core capabilities e capacidades absortivas. O cluster 2 envolve as discussões a respeito da inovação disruptiva e suas implicações para as empresas e mercados. Já os trabalhos que formam o cluster 3 , tratam da inovação disruptiva e tecnologias disruptivas.

A partir desses clusters, é possível entender melhor como as pesquisas tem se concentrado nessa área e identificar os caminhos que a investigação cientifica tem tomado, de maneira que seja possível avaliar que outras frentes de estudo podem ser consideradas. Apesar das relações associando inovação disruptiva digital e capacidades dinâmicas ainda não terem um impacto significativo na literatura, isso pode ser um reflexo do fato de que o campo ainda precisa ser mais explorado. É importante destacar que os novos modelos de negócios podem ajudar a aprimorar a visão da literatura sobre as capacidades dinâmicas em resposta à inovação disruptiva digital.

Como limitação da pesquisa, vale ressaltar que apenas a base de dados da WOS foi utilizada, e outras bases de dados podem apresentar resultados mais completos. Para trabalhos futuros, sugere-se a junção de trabalhos ancorados em outras bases, além da adoção de outras técnicas de análise bibliométrica, a fim de confirmar ou refutar os resultados obtidos nesta pesquisa.

\section{Referências}

Abernathy, W. J., \& Clark, K. B. (1985). Innovation: Mapping the winds of creative destruction.

Research Policy, 14(1), 3-22. https://doi.org/10.1016/0048-7333(85)90021-6

Adner, R., \& Snow, D. (2010). Old technology responses to new technology threats: Demand heterogeneity and technology retreats. Industrial and Corporate Change, 19(5), 1655-1675. https://doi.org/10.1093/icc/dtq046

Adomavicius, G., Bockstedt, J. C., Gupta, A., \& Kauffman, R. J. (2007). Technology roles and paths of influence in an ecosystem model of technology evolution. Information Technology and Management, 8(2), 185-202. https://doi.org/10.1007/s10799-007-0012-z

Anderson, P., \& Tushman, M. L. (1990). Technological Discontinuities and Dominant Designs: A Cyclical Model of Technological Change. Administrative Science Quarterly, 35(4), 604-633. 
https://doi.org/10.2307/2393511

Bower, J. L., \& Christensen, C. M. (1995). Disruptive Technologies: Catching the Wave. Harvard Business Review, 73, 43-53. https://hbr.org/1995/01/disruptive-technologies-catching-thewave

Christensen, C. M., \& Bower, J. L. (1996). Customer Power, Strategic Investment, and the Failure of Leading Firms. Strategic Management Journal, 17(3), 197-218. https://doi.org/10.1002/(SICI)1097-0266(199603)17:3<197::AID-SMJ804>3.0.CO;2-U

Christensen, C. M., \& Raynor, M. E. (2003, setembro 1). Why Hard-Nosed Executives Should Care About Management Theory. Harvard Business Review. https://hbr.org/2003/09/why-hardnosed-executives-should-care-about-management-theory

Christensen, C. M., Raynor, M. E., Rory, M., \& McDonald, R. (2015). What is disruptive innovation? Harvard Business Review, 93(12), 44-53. https://doi.org/10.1353/abr.2012.0147

Cobo, M. j., López-Herrera, A. g., Herrera-Viedma, E., \& Herrera, F. (2011). Science mapping software tools: Review, analysis, and cooperative study among tools. Journal of the American Society for Information Science and Technology, 62(7), 1382-1402. https://doi.org/10.1002/asi.21525

Collis, D. J. (1994). Research Note: How Valuable Are Organizational Capabilities? Strategic Management Journal, 15, 143-152. https://www.jstor.org/stable/2486815

Eisenhardt, K. M., \& Martin, J. A. (2000). Dynamic capabilities: What are they? Strategic Management Journal, 21(10-11), 1105-1121. https://doi.org/10.1002/10970266(200010/11)21:10/11<1105::AID-SMJ133>3.0.CO;2-E

El Sawy, O. A., Malhotra, A., Park, Y., \& Pavlou, P. A. (2010). Research Commentary -Seeking the Configurations of Digital Ecodynamics: It Takes Three to Tango. Information Systems Research, 21(4), 835-848. https://doi.org/10.1287/isre.1100.0326

Elbanna, A., \& Newman, M. (2016). Disrupt the Disruptor: Rethinking ' Disruption ' in Digital Innovation. Mcis 2016 Proceedings, 58. https://aisel.aisnet.org/mcis2016/58/

Helfat, C. E., Finkelstein, S., Mitchel, W., Peteraf, M., Singh, H., Teece, D. J., \& Winter, S. G. ([s.d.]). 
Dynamic Capabilities: Understanding Strategic Change in Organizations / Wiley.

https://www.wiley.com/en-

us/Dynamic+Capabilities\%3A+Understanding+Strategic+Change+in+Organizations-p9781405135757

Helfat, C. E., \& Peteraf, M. A. (2003). The dynamic resource-based view: Capability lifecycles. Strategic Management Journal, 24(10), 997-1010. https://doi.org/10.1002/smj.332

Henderson, R. M., \& Clark, K. B. (1990). Architectural Innovation: The Reconfiguration of Existing Product Technologies and the Failure of Established Firms. Administrative Science Quarterly, 35(1), 9-30. https://doi.org/10.2307/2393549

Karimi, J., \& Walter, Z. (2015). The role of dynamic capabilities in responding to digital disruption: A factor-based study of the newspaper industry. Journal of Management Information Systems, 32(1), 39-81. https://doi.org/10.1080/07421222.2015.1029380

Leonard-Barton, D. (1992). Core Capabilities and Core Rigidities: A Paradox in Managing New Product Development. Strategic Management Journal, 13, 111-125. https://www.jstor.org/stable/2486355

Li, D., \& Liu, J. (2014). Dynamic capabilities, environmental dynamism, and competitive advantage: Evidence from China. Journal of Business Research, 67(1), 2793-2799. https://doi.org/10.1016/j.jbusres.2012.08.007

Loubère, L. \& Ratinaud, P. (2014). Documentation IraMuTeQ 0.6 alpha 3 - version 0.1 [Computer software]

Markides, C. (2006). Disruptive innovation: In need of better theory. Journal of Product Innovation Management, 23(1), 19-25. https://doi.org/10.1111/j.1540-5885.2005.00177.x

Meirelles, D. S. e, \& Camargo, Á. A. B. (2014). Dynamic Capabilities: What Are They and How to Identify Them? Revista de Administração Contemporânea, 18(spe), 41-64. https://doi.org/10.1590/1982-7849rac20141289

Nagy, D., Schuessler, J., \& Dubinsky, A. (2016). Defining and identifying disruptive innovations. 
Industrial Marketing Management, 57, 119-126.

https://doi.org/10.1016/j.indmarman.2015.11.017

O'Reilly, C. A., \& Tushman, M. L. (2004, abril 1). The Ambidextrous Organization. Harvard Business Review. https://hbr.org/2004/04/the-ambidextrous-organization

Pasadeos, Y., Phelps, J., \& Kim, B.-H. (1998). Disciplinary Impact of Advertising Scholars: Temporal Comparisons of Influential Authors, Works and Research Networks. Journal of Advertising, 27(4), 53-70. https://doi.org/10.1080/00913367.1998.10673569

Pritchard, A. (1969). Statistical bibliorgrahy or bibliometricas? Journal of Documentation. 25 (4), 348349.

Riemer, K., \& Johnston, R. B. (2019). Disruption as worldview change: A Kuhnian analysis of the digital music revolution. Journal of Information Technology, 34(4), 350-370. https://doi.org/10.1177/0268396219835101

Salviati, M. E. Manual do Aplicativo Iramuteq (versão 0.7 Alpha 2 e R Versão 3.2.3). Planaltina. (2017). http://iramuteq.org/documentation/fichiers/anexo-manual-do-aplicativo-iramuteq-parmariaelisabeth-salviati

Shafique, M. (2013). Thinking Inside the Box? Intellectual Structure of the Knowledge Base of Innovation Research (1988-2008). Strategic Management Journal, 34(1), 62-93. https://www.jstor.org/stable/23362649

Shang, T., Miao, X., \& Abdul, W. (2019). A historical review and bibliometric analysis of disruptive innovation. International Journal of Innovation Science, 11(2), 208-226. https://doi.org/10.1108/IJIS-05-2018-0056

Si, S., \& Chen, H. (2020). A literature review of disruptive innovation: What it is, how it works and where it goes. Journal of Engineering and Technology Management, 56, 101568. https://doi.org/10.1016/j.jengtecman.2020.101568

Skog, D. A., Wimelius, H., \& Sandberg, J. (2018). Digital Disruption. Business \& Information Systems Engineering, 60(5), 431-437. https://doi.org/10.1007/s12599-018-0550-4 
Small, H. (1999). Visualizing science by citation mapping. Journal of the American Society for Information Science, 50(9), 799-813. https://doi.org/10.1002/(SICI)10974571(1999)50:9<799::AID-ASI9>3.0.CO;2-G

Teece, D. J. (2007). Explicating dynamic capabilities: The nature and microfoundations of (sustainable) enterprise performance. Strategic Management Journal, 28(13), 1319-1350. https://doi.org/10.1002/smj.640

Teece, D. J., Pisano, G., \& Shuen, A. (1997). Dynamic capabilities and strategic management. Strategic Management Journal, 18:7, 509-533. https://doi.org/10.1142/9789812796929_0004

Tushman, M. L., \& Anderson, P. (1986). Technological Discontinuities and Organizational Environments. Administrative Science Quarterly, 31(3), 439-465. https://doi.org/10.2307/2392832

van Eck, N. J., \& Waltman, L. (2010). Software survey: VOSviewer, a computer program for bibliometric mapping. Scientometrics, 84(2), 523-538. https://doi.org/10.1007/s11192-009-0146-3

Wang, C. L., \& Ahmed, P. K. (2007). Dynamic capabilities: A review and research agenda. International Journal of Management Reviews, 9(1), 31-51. https://doi.org/10.1111/j.14682370.2007.00201.x

Winter, S. G. (2003). Understanding dynamic capabilities. Strategic Management Journal, 24(10), 991995. https://doi.org/10.1002/smj.318

Yoo, Y., Henfridsson, O., \& Lyytinen, K. (2010). Research Commentary -The New Organizing Logic of Digital Innovation: An Agenda for Information Systems Research. Information Systems Research, 21(4), 724-735. https://doi.org/10.1287/isre.1100.0322

Yu, D., \& Hang, C. C. (2010). A Reflective Review of Disruptive Innovation Theory. International Journal of Management Reviews, 12(4), 435-452. https://doi.org/10.1111/j.1468-2370.2009.00272.x

Zahra, S. A., \& George, G. (2002). Absorptive Capacity: A Review, Reconceptualization, and Extension. The Academy of Management Review, 27(2), 185-203. https://doi.org/10.2307/4134351

Zollo, M., \& Winter, S. G. (2002). Deliberate Learning and the Evolution of Dynamic Capabilities. 
Organization Science, 13(3), 339-351. https://www.jstor.org/stable/3086025

Zupic, I., \& Čater, T. (2015). Bibliometric Methods in Management and Organization. Organizational Research Methods, 18(3), 429-472. https://doi.org/10.1177/1094428114562629 